\title{
PERCEPCIÓN DEL CAMBIO CLIMÁTICO Y RESPUESTAS LOCALES DE ADAPTACIÓN: EL CASO DEL TURISMO RURAL ${ }^{1}$
}

\author{
$M^{a}$ Belén Gómez Martín \\ Xosé A. Armesto López. \\ Martí Cors Iglesias \\ Universidad de Barcelona
}

\section{RESUMEN}

Desde el punto de vista del sector turístico, el conocimiento científico de las alteraciones producidas en el clima y de los impactos sectoriales derivados se configura como un aspecto clave para el desarrollo de las políticas de adaptación y mitigación del cambio climático. Sin embargo, todo ello resulta insuficiente si no va acompañado del conocimiento de las actitudes públicas, creencias y percepciones del riesgo que muestran los diferentes actores interesados. Apoyándose en una metodología mixta que incluye el enfoque cuantitativo y el cualitativo, este artículo explora la percepción del riesgo asociado al cambio climático que presentan actores clave del turismo rural. La aproximación planteada ha permitido conocer cómo se perciben los impactos del cambio climático, sus posibles repercusiones en los negocios de turismo rural y las respuestas locales de adaptación desarrolladas hasta el momento. La investigación también ha permitido detectar barreras subjetivas a las acciones de adaptación que podrían dificultar la lucha frente al fenómeno. Desde el punto de vista geográfico, la investigación se acota al Alt Empordà, una comarca catalana situada en el extremo nororiental de la conocida marca turística Costa Brava.

Palabras clave: turismo rural, cambio climático, percepción del riesgo, impactos, adaptación.

Recibido: 9 de septiembre de 2015

Devuelto para su revisión: 5 de febrero de 2016

Aceptado: 17 de marzo de 2016

Departamento de Geografia Física y Análisis Geográfico Regional. Universidad de Barcelona. C/ Montalegre, 6.08001 BARCELONA (España)-E-mail: bgomez@ub.edu, armesto@ub.edu, marti.cors@ub.edu

1 Este aportación ha sido realizada en el marco del proyecto de investigación del Plan Nacional de I+D+i del Ministerio de Economía y Competitividad del Gobierno de España, con referencia CSO2011-23404 y título Estrategias de adaptación planificada para la reducción de la vulnerabilidad del turismo litoral del Mediterráneo español al cambio climático, cuya investigadora principal es la Dra. M. Belén Gómez Martín (Universidad de Barcelona). 


\title{
Climate change perception and local adaptation responses: rural tourism as a case study
}

\begin{abstract}
From the point of view of tourism, scientific knowledge of the alterations in climate and consequent sector impacts is set up as a key issue for the development of policies for adaptation and mitigation of climate change. However, all this is insufficient unless it is accompanied by the knowledge of public attitudes, beliefs and perceptions of risk showing the different stakeholders. This paper explores, based on a mixed methodology that it includes quantitative and qualitative approach, the perception of risk associated with climate change that present key actors in rural tourism. The proposed approach has allowed knowing how the impacts of climate change, its potential impacts on rural tourism businesses and local adaptation responses developed so far are perceived. Research has also enabled to detect subjective barriers to the adaptation actions that could hinder the fight against the phenomenon. From a geographical point of view, research is focused in Alt Empordà, a Catalan small region located in the northeast of the well-known Costa Brava tourism brand.
\end{abstract}

Keywords: rural tourism, climate change, risk perception, impacts, adaptation.

\section{INTRODUCCIÓN}

Aunque el cambio climático ha sido identificado como la principal amenaza para el desarrollo del turismo en el siglo XXI, la investigación en este campo -a pesar de haber experimentado en los últimos años una atención creciente- sufre un cierto retraso frente a la llevada a cabo en relación a otros sectores y/o actividades económicas (Becken, 2013; Gómez Martín, 2005a; Olcina, 2012; Wolfsegger et al., 2008). Un reciente estudio de Becken (2013) señala que el $50 \%$ de las publicaciones sobre turismo y cambio climático realizadas hasta el momento se han relacionado con el estudio de impactos y estrategias de adaptación; los trabajos sobre mitigación han representado el 34\% y las publicaciones sobre políticas tan solo han significado el 8\%. En este contexto, el estudio de la percepción del riesgo asociado al cambio climático emerge en los últimos años como un aspecto clave por la influencia que ejerce en la proactividad de los actores y, en consecuencia, en la capacidad de respuesta frente al fenómeno, ya sea a través de la adopción de diferentes estrategias de adaptación o de mitigación (Becken et al., 2015; Campos et al., 2013; Hall, 2006; Mertz et al., 2009). Conocer la percepción del riesgo asociado al cambio climático, las respuestas locales para afrontar este reto ambiental y las barreras que dificultan las capacidades locales de adaptación resultan fundamentales para la planificación del sector a medio y largo plazo (Belle y Bramwell, 2005; Eriksen y Selboe, 2012; Hall 2006; Klint et al., 2012).

Trabajos destacados en este sentido han sido, entre otros, los realizados por Belle y Bramwell (2005), Buckley (2008), Buzinde et al. (2010), Gössling et al. (2006), McEvoy et al. (2008) o Valls y Sardá (2009) para el turismo de sol y playa; o los realizados por Prideaux et al. (2010), Scott et al. (2008) o Trawöger (2014) para el turismo en regio- 
nes de montaña asociado a los deportes de invierno. Los sujetos objeto de atención han sido fundamentalmente turistas (Gössling et al., 2012), pero también actores del ámbito de la oferta, así como agentes y operadores del mercado (Wyss et al., 2014; Saarinen y Tervo, 2010; Strobl et al., 2011). Los enfoques manejados en la investigación han sido cuantitativos y cualitativos, siendo las encuestas, las entrevistas, el Delphi y los grupos de discusión las herramientas más utilizadas. Aunque los resultados son complejos y variados dependiendo del ámbito territorial de estudio, la modalidad turística y los actores considerados, existen aspectos comunes de interés. De este modo, los participantes en los estudios, aunque han detectado evidencias del cambio climático en sus entornos, tienden a minimizar las posibles consecuencias del mismo sobre la actividad, depositando una confianza excesiva en las opciones tecnológicas de adaptación. También las diversas investigaciones realizadas han coincidido en señalar que el fenómeno del cambio climático ha sido utilizado por el turismo para justificar y legitimar ciertas actuaciones de adaptación de fuerte impacto ambiental.

En el ámbito del turismo, queda todavía mucho por investigar en relación a la percepción del riesgo asociado al cambio climático: la consideración de modalidades turísticas de gran trascendencia territorial -como el turismo rural- debe configurarse en los próximos años en un aspecto prioritario de atención (Scott et al., 2012). El turismo rural se configura como una modalidad turística que, a diferencia del de sol y playa o el turismo de nieve, muestra una menor dependencia de los recursos climáticos (Gómez Martín, 2005b). El turismo rural, al igual que el turismo de naturaleza, muestra una gran dependencia del recurso paisaje. El paisaje constituye un recurso turístico esencial para esta modalidad (Cánoves et al., 2005; Espejo, 2011; Nogué, 1989), entendiéndolo, en palabras de Hernández (2009: 170), como "un concepto complejo, resultado de la combinación de aspectos diversos como son los naturales, los históricos y los funcionales, pero que adquiere también valor simbólico y subjetivo al ser considerado reflejo de la herencia cultural de un pueblo, de su identidad y resultado de unas prácticas históricas ejercidas por un grupo humano sobre el territorio". Existe un conocimiento limitado sobre cómo se perciben los impactos del cambio climático sobre los paisajes que dan sustento a esta modalidad y las repercusiones que ello puede tener sobre los negocios de turismo rural. Explorar esta cuestión resulta extremadamente complejo ya que la actual multifuncionalidad de los paisajes rurales recomienda la consideración de los diversos actores que intervienen, tanto en su configuración y gestión como en su consumo.

El trabajo aquí presentado quiere explorar la percepción del riesgo asociado al cambio climático que presentan actores clave del turismo rural. Concretamente, se pretende conocer cómo se perciben los impactos del cambio climático sobre los paisajes, así como sus posibles repercusiones en los negocios de turismo rural. Del mismo modo, la aproximación planteada pretende conocer las respuestas locales de adaptación desarrolladas por los actores interesados o susceptibles de ser implementadas por ellos en el futuro. Desde el punto de vista geográfico, la investigación se acota al Alt Empordà, una comarca catalana situada en el extremo nororiental de la conocida marca turística Costa Brava. Se trata de un espacio marcado por la proximidad existente entre el mar y la montaña que, con apenas una superficie de $1357,5 \mathrm{~km}^{2}$, concentra una amplia oferta de alojamiento turístico que la sitúa en una posición muy destacada dentro del escenario turístico catalán. 


\section{2. ÁREA DE ESTUDIO Y PLANTEAMIENTO DE LA PROBLEMÁTICA}

La comarca del Alt Empordà se configuró históricamente como uno de los paisajes más interesantes de Cataluña tanto desde la perspectiva biofísica como desde la cultural (Serra et al., 2004). La unidad paisajística más característica de la comarca del Alt Empordà es la "Plana" del Empordà, una amplia llanura agrícola abierta al mar, colmatada de sedimentos detríticos del cuaternario, aportados por los distintos cursos fluviales que provienen de las estribaciones más orientales de los Pirineos. Es una llanura rodeada por una serie de alineaciones montañosas que configuran otras subunidades paisajísticas características de la zona: "Terraprims", "Garrotxa d'Empordà", "Els Aspres”, "Cap de Creus" y "Salinesl'Albera" (Alberti y Gordi, 2009) (Figura 1).

\section{Figura 1 \\ UNIDADES DEL PAISAJE DEL ALT EMPORDÀ}

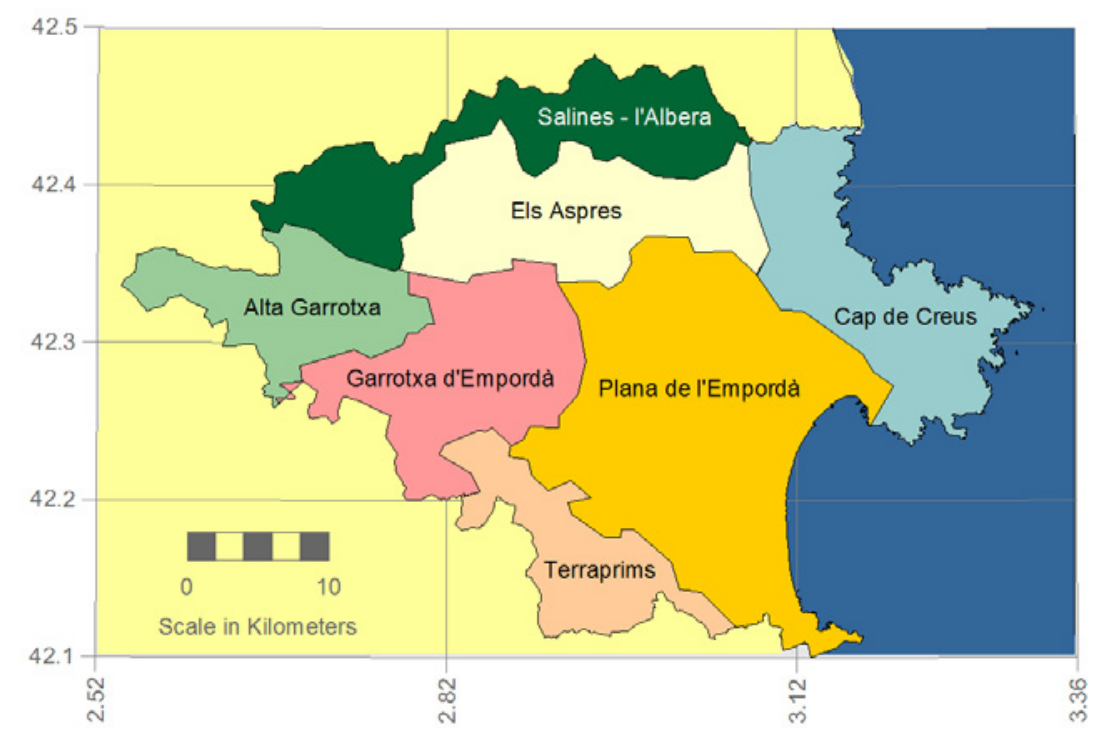

La actividad productiva agraria ${ }^{2}$ en el Alt Empordà es un elemento fundamental para la interpretación del paisaje y su configuración estética. Tan solo los municipios

2 El sector agrario de esta comarca catalana es el producto de múltiples influencias y dinámicas externas e internas, y no escapa a las tendencias generales que se perciben tanto a escala catalana como española o europea (aumento de la importancia de la superficie forestal, tecnificación creciente, aumento de la dimensión económica de las explotaciones, reajuste mercantil, etc.). De cualquier forma, sí que presenta ciertas características que le dan una significación un tanto particular: a) el mantenimiento del número de explotaciones (en el último período intercensal -1999/2009- el descenso solo fue del 0,004\% mientras que en el conjunto de Cataluña el decremento fue del 10\%); b) el incremento de la SAU (en la comarca fue del 20,5\%, mientras en Cataluña no hubo una variación significativa permaneciendo prácticamente estable su superficie) y; c) la combinación de usos del suelo al tratarse de un área turística de primera magnitud (en los últimos años la superficie urbana y la dedicada a zonas 
del litoral, altamente urbanizados como consecuencia del fuerte crecimiento turístico experimentado hasta principios de los 90, suponen una excepción a lo señalado. Estos presentan una importante artificialización que ha provocado una "fragmentación ecológica del mosaico agroforestal característico del antiguo paisaje rural" (Martí y Pintó, 2012: 239). Teniendo en cuenta esto, para el caso del Alt Empordà, la máxima actividad productiva agrícola tiene lugar en la "Plana" del Empordà: en ella, los herbáceos de secano y los frutales de regadío configuran los usos predominantes. El viñedo y el olivo, están muy presentes en los "Aspres" y han revalorizado la actividad productiva de su paisaje. En las tierras definidas como "Cap de Creus" se produjo un pronunciado abandono de la actividad agraria, aunque hoy en día y casi siempre en algunos fondos de valle, parece haber una recuperación de la viña orientada a la elaboración de vinos de calidad, algunos bajo preceptos ecológicos. La caracterización del paisaje actual del área de "Salines-Albera" es la de un mosaico en el que se alternan bosques esclerófilos en el piso basal, bosques de caducifolios en los pisos intermedios y prados en su parte más elevada. En la denominada "Alta Garrotxa" el dominio de la vegetación espontanea, con predominancia de las especies arbóreas esclerófilas (sobre todo la encina), es mayoritario. Esta tónica de ocupación del suelo se extiende hacia la "Garrotxa d'Empordà", en la que, a pesar de seguir siendo el paisaje mayoritario el forestal, aparecen más bosques de pinos y una mayor presencia de tierras de labor de secano. Por último, en el área de "Terraprims" el mosaico agroforestal se torna más evidente distribuyéndose los usos agrario y forestal casi de forma equilibrada.

Este paisaje, de fuerte impronta agraria, ha jugado un importante papel en el desarrollo del turismo rural de esta comarca por los múltiples valores atribuidos al mismo (literario y artístico, estético, ecológico, productivo, social, histórico, religioso-espiritual, identitario). El turismo rural en la comarca del Alt Empordà tiene sus inicios a principios de los años noventa del siglo XX con la apertura de los primeros establecimientos. Desde su aparición, el sector del turismo rural ha experimentado un fuerte crecimiento en toda la zona, en consonancia con el resto de las comarcas situadas en la mitad norte de Cataluña (Prat y Cànoves, 2014). En la actualidad el Alt Empordà ostenta la primera posición a nivel de Cataluña en cuanto a volumen de oferta, con un total de 155 establecimientos de turismo

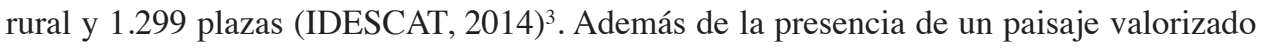

industriales, comerciales y a infraestructuras de comunicación no ha cesado de crecer sobre todo en el ámbito territorial de la Plana). Además, hay que tener en cuenta, en relación con las nuevas tendencias integradoras entre actividad productiva y respeto medioambiental, por una parte el destacado peso de la superficie inscrita en el registro de la producción integrada (más de 1.200 ha en 2012, el $4 \%$ del total catalán) y, sobre todo la creciente importancia relativa de la superficie inscrita en el registro del Consejo Catalán de la Producción Agraria Ecológica (en el momento del trabajo de campo las estadísticas reflejaban que 4.618 ha habían sido dadas de alta - casi el $5 \%$ del total catalán-; habiéndose doblado el número de explotaciones y casi multiplicado por seis la superficie declarada desde 2009. Un incremento mucho más destacado que la media catalana -incremento del $33 \%$ en superficie y del $48 \%$ en número de productores-).

3 En el momento de realizar el trabajo de campo, 142 establecimientos y 1.184 plazas. De estos 142 establecimientos, 36 correspondían a establecimientos de agroturismo, en los que el titular era agricultor profesional y obtenía rentas agrarias, ganaderas o forestales, y donde los turistas podían conocer las actividades propias de la explotación agraria, y 106 correspondían a alojamientos rurales, en los que su titular no estaba obligado a obtener rentas agrícolas, ganaderas o forestales, pero debía residir en la misma comarca o vivienda, dependiendo de la modalidad. 
que actúa como principal recurso y atractivo turístico en la actividad, otras causas ayudan a explicar también este auge y liderazgo: a) el apoyo al sector del turismo rural a través de las políticas públicas de desarrollo local y rural en el marco de la Unión Europea -programas LEADER y PRODER-; b) la consolidación de un nuevo modelo turístico de desarrollo caracterizado por la diversificación y complementariedad de productos y servicios turísticos como una nueva estrategia de desarrollo económico y territorial; y c) la presencia de un destino turístico maduro y consolidado de sol y playa y residencial (Costa Brava) que genera sinergias de desarrollo hacia otros tipos de turismo (rural, activo, cultural) (Gómez Martín et al., 2014).

La valorización turística del paisaje en esta comarca queda reflejada en la Carta de Paisaje del Alt Empordà (Alberti y Gordi, 2009), un documento de referencia para la gestión y planificación del territorio que emana de la Ley 8/2005 de Protección, Ordenación y Gestión del Paisaje de Cataluña. El paisaje ampurdanés es un activo fundamental a tener en cuenta en los procesos de desarrollo; de ahí su interés por protegerlo, ordenarlo y gestionarlo. Pero en la protección y ordenación del paisaje no deben despreciarse los cambios ambientales que se vienen registrando a escala global. La dinámica de los paisajes rurales de esta comarca no sólo está determinada por los cambios en los sistemas económicos y sociales. También los cambios en los sistemas naturales -aunque, también inducidos por el hombre como, por ejemplo, el del cambio climático- pueden jugar un importante papel en su transformación. En este sentido, los cambios atmosféricos proyectados para el área de estudio ${ }^{4}$ pueden generar impactos que afectarán con diferente signo, tanto a los ecosistemas terrestres de los paisajes rurales en sí mismos, como a las actividades económicas que sobre ellos se desarrollan. Las modificaciones en los parámetros climáticos provocarán cambios en la estructura, funcionamiento y distribución de los ecosistemas de los paisajes rurales que podrán comprometer sus actuales funciones productivas, ambientales y sociales (Figura 2).

Las modificaciones en el paisaje del Alt Empordà (Figura 2) generarán cambios en su atractivo turístico lo que, a su vez, provocará cambios en la imagen turística de la comarca. Todo ello podría repercutir en la toma de decisiones del turista y, con ello, afectar a los flujos que visitan la comarca. Estos cambios se sumarán a (o interactuarán con) los impactos directos provocados por el fenómeno. En este último sentido, las modificaciones en los parámetros climáticos supondrán cambios notables en la aptitud climático-turística de la zona que podrían concretarse en una favorable ampliación de las temporadas turísticas al prolongarse la duración del verano (aunque con una disminución en los niveles de confort), pero sobre todo la duración de la primavera y el otoño, estaciones altamente favorables para la práctica del turismo rural (Barrios y Ibañez, 2015; Gómez y Martínez,

4 Los estudios sobre cambio climático (según modelo HadGEM1, escenario A2) señalan para el ámbito de estudio que, en los próximos años, la temperatura tenderá a aumentar, como ya lo ha hecho en los últimos (1975-1998: $+0.7^{\circ} \mathrm{C} /$ década), se acrecentará la variabilidad espacial y temporal de las precipitaciones y seguirá subiendo el nivel de mar (2,5 mm/año en los últimos 15 años). Los escenarios regionales para el período 20102050 sugieren para nuestro ámbito de trabajo un incremento en la temperatura media de $1-1,5^{\circ} \mathrm{C}$, mientras que para las temperaturas máximas del período estival los cambios pueden alcanzar los $3-4^{\circ} \mathrm{C}$; éstos cambios en las temperaturas se señalan más pronunciados en las zonas interiores que no en primera línea de costa. La precipitación se verá considerablemente reducida, pudiendo ser la contracción de hasta un $40 \%$ en el período estival (Ribas et al., 2010). 
2012; Gómez et al., 2014; Hein et al., 2009; Martínez y Gómez, 2012; Rutty y Scott, 2010). Frente a este efecto positivo, cabe tener en cuenta que la reducción de la precipitación podría generar una disminución de las aportaciones hídricas que obligaría a replantear el manejo de los actuales recursos hídricos para hacer frente a las futuras y posiblemente crecientes demandas de agua (García et al., 2011; Hof y Schmitt, 2011; Iglesias et al., 2011; Martínez, 2015; Rico et al., 2009).

\section{Figura 2 \\ IMPACTOS DEL CAMBIO CLIMÁTICO \\ EN EL PAISAJE DEL ALT EMPORDÀ}

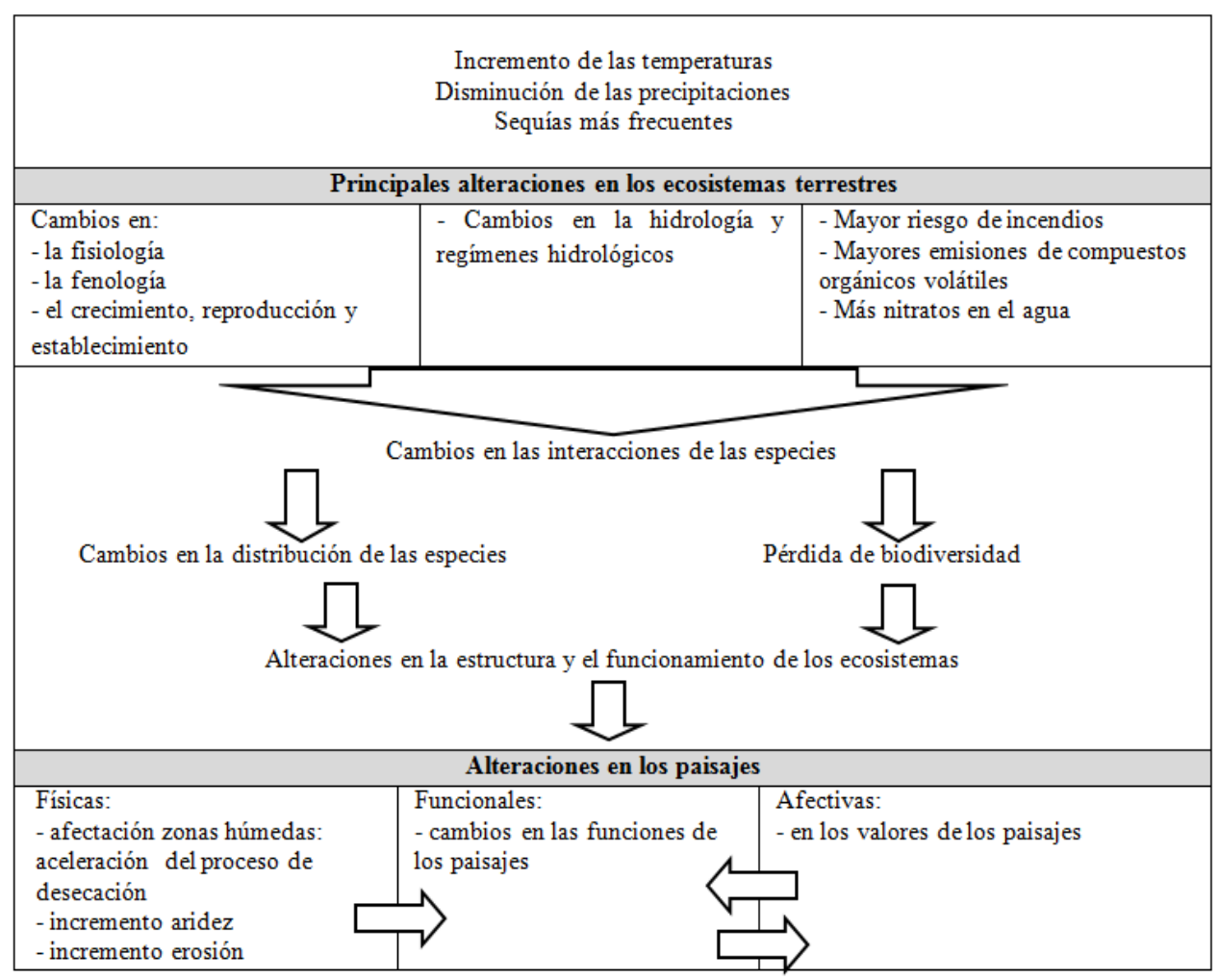

Fuente: modificación realizada a partir de la propuesta de Hughes (2000).

Todas estas amenazas y oportunidades planteadas por el fenómeno han propiciado el desarrollo de numerosas actuaciones y políticas de lucha contra el cambio climático (sectoriales o no) que de forma directa o indirecta han repercutido en la comarca y que, en la mayoría de los casos, suponen una traslación de programas, planes y acciones de ámbito europeo o estatal al ámbito regional y local. De este modo, a escala regional, el gobierno de la Generalitat de Cataluña ha desarrollado una importante actividad en materia de cambio climático que ha sido vehiculizada a través de diversos tipos de ins- 
trumentos como la planificación ${ }^{5}$, la autorregulación ${ }^{6}$, la gobernanza ${ }^{7}$, la incentivación ${ }^{8}$ y la información y participación ${ }^{9}$. Las acciones se repiten a escala local ${ }^{10}$.

A pesar de los efectos beneficiosos que el cambio climático generará sobre la aptitud climático-turística de la comarca, el turismo rural del Alt Empordà se muestra vulnerable al fenómeno principalmente por los cambios que pueden experimentarse en los paisajes que hoy actúan como marco de referencia (recurso y atractivo turístico), pero también por la disminución de los recursos hídricos que pueden comprometer el abastecimiento y, con ello, el mantenimiento de las actividades económicas, tal y como se desarrollan hoy. Es por ello por lo que conocer la percepción del riesgo que muestran los actores interesados puede ser de interés en la acción frente al fenómeno.

\section{METODOLOGÍA}

La investigación aquí realizada hace uso de una metodología mixta que incluye el enfoque cuantitativo y el cualitativo (Tashakkori y Teddlie 1998, 2010), siguiendo la terminología de Wilbanks (2003) localizado o geográficamente confinado a los principales destinos turísticos del área de estudio. Para nuestro caso, esta aproximación se configura como la

5 Algunos ejemplos son el Plan Marco de Mitigación del Cambio Climático 2008-2012, el Plan de Energía y Cambio Climático (PECAC 2012 a 2020) o la Estrategia Catalana de Adaptación al Cambio Climático (ESCACC 2013 a 2020). A estos deben sumarse planificaciones o actuaciones de ámbito sectorial donde también se han abordado los aspectos relativos al fenómeno: el Plan General de Política Forestal, el Plan Estratégico de Turismo, el Plan de Desarrollo Rural (que concreta parte de las directrices que emanan de la PAC), la aplicación de políticas en materia de recogida selectiva de residuos o los incentivos a la mejora en la eficiencia energética, por citar sólo algunos ejemplos del ámbito temático que se aborda en este artículo (Generalitat de Cataluña, 2015).

6 El ejemplo más significativo es el Programa de Acuerdos Voluntarios para la reducción de GEI, creado en 2010 y que ya cuenta con más de 120 organizaciones adheridas y que han puesto en marcha más de 600 actuaciones para la reducción de sus emisiones. También es importante destacar el impulso al ecodiseño y el apoyo a la implantación de otros instrumentos voluntarios como son los sistemas de gestión ambiental o de ecoetiquetado de productos y servicios que, aunque no son específicos del cambio climático, también tratan algunos de sus aspectos (Generalitat de Cataluña, 2015).

7 El ejemplo más claro es la Comisión Interdepartamental del Cambio Climático, creada en 2007, con el objetivo de disponer de un órgano que facilite la coordinación de las diferentes actuaciones de los Departamentos que por razón de sus competencias sectoriales más incidencia tienen en el ámbito del cambio climático, ya sea en materia de mitigación o adaptación. Otro ejemplo, este muy reciente, es la aprobación del Proyecto de Ley del Cambio Climático en Cataluña (Generalitat de Cataluña, 2016).

8 Desde el gobierno autonómico se han puesto en marcha convocatorias de ayudas que directa o indirectamente tienen implicaciones en materia de cambio climático. Algunos ejemplos son convocatorias de ayudas para el cálculo de la huella de carbono en productos agrícolas, para la implantación de medidas de ahorro y eficiencia energética en edificios o en la iluminación, para el desarrollo de la movilidad eléctrica o con medios no motorizados, o para el desarrollo de planes de adaptación en el mundo local (Generalitat de Cataluña, 2015).

9 También en este ámbito han sido muchas las actuaciones desarrolladas. En primer lugar, hay que tener presente que en la aprobación de la mayoría de los planes indicados anteriormente, se incluyen procesos de Información y participación. Asimismo, Cataluña ha sido la sede de importantes eventos relacionados con el cambio climático (Generalitat de Cataluña, 2015).

10 Planificaciones y actuaciones de ámbito sectorial donde se abordan aspectos relativos al cambio climático (Agenda 21-Plan de Acción Comarcal para la Sostenibilidad, Plan de Acción Sectorial en el ámbito del desarrollo turístico, Plan Estratégico de la Producción Agraria Ecológica del Alt Empordà, Plan de Acción para la Energía Sostenible, Plan de Acción Local para la Sostenibilidad, etc.); adhesión de numerosos municipios ampurdaneses al Pacto de Alcaldes por una energía local sostenible, etc. 
mejor manera de obtener información variada sobre un fenómeno complejo que afecta, con diferente signo, a los actores que se interrelacionan en el territorio (Sui y DeLyser 2012; DeLyser y Sui 2013, 2014). La combinación de estos enfoques, tal y como se ha demostrado en otras investigaciones (Becken, 2005; Lorenzoni et al., 2007), permite realizar un cierto grado de triangulación de los hallazgos y posibilita complementar los resultados. Por ello, este doble enfoque permite explorar cómo se perciben los impactos del cambio climático sobre los paisajes del área de estudio, así como sus posibles repercusiones en los negocios de turismo rural. Del mismo modo, esta aproximación resulta útil para conocer las estrategias de adaptación desarrolladas por los actores interesados o susceptibles de ser implementadas por ellos en el futuro y/o detectar barreras para la adaptación.

Los datos fueron obtenidos de tres fuentes, a partir de entrevistas y/o encuestas (Tabla 1): propietarios de establecimientos de agroturismo, propietarios de establecimientos de alojamiento rural y productores agrarios ecológicos. El hecho de que, por un lado, la actividad productiva agraria en el Alt Empordà sea un elemento fundamental para la interpretación del paisaje y su configuración estética (Armesto et al., 2014; Llausàs et al., 2009) y, por otro, el hecho de que en el desarrollo del turismo rural de la comarca haya jugado un importante papel este paisaje de fuerte impronta agraria, justifica la elección de las fuentes.

\section{Tabla 1 \\ METODOLOGÍA UTILIZADA}

\begin{tabular}{lccc}
\hline Fuentes o Actores & Encuestas & Entrevistas & Universo \\
\hline Propietarios establecimientos agroturismo & & 8 & 36 \\
Propietarios alojamientos rurales & 54 & 6 & 106 \\
Productores agrarios ecológicos & & 14 & 29 \\
\hline
\end{tabular}

Las entrevistas con los propietarios de los establecimientos de agroturismo se llevaron a cabo en el propio negocio e incluían, además, la visita y reconocimiento del mismo. En total se realizaron 8 entrevistas semi-estructuradas durante los años 2011 y 2012. El 57\% de los entrevistados fueron mujeres y el $43 \%$ hombres, con un edad media de 55 años.

Las entrevistas con los productores agrarios de la comarca se llevaron a cabo en la propia explotación y también incluían el reconocimiento in situ. En total se realizaron 14 entrevistas semi-estructuradas desde finales de 2011 hasta finales de 2012. El entrevistado medio fue un varón de entre 40 y 55 años, propietario de la explotación, trabajador a tiempo completo (con ayudas familiares), que manejaba una superficie ecológica en su totalidad de entre 25 y 50 hectáreas en las que las producciones predominantes fueron forrajes, cereales, cultivos hortícolas y frutales, ganado ovino y caprino y producción de aceite de oliva para autoconsumo.

Finalmente, los propietarios de establecimientos de alojamiento rural fueron cubiertos a través de 6 entrevistas semi-estructuradas y 54 encuestas personales, realizadas durante la anualidad 2013 en los propios establecimientos. Estas últimas fueron administradas según muestreo aleatorio simple, no siendo coincidentes con los establecimientos entre- 
vistados seleccionados (en este último caso, el $63 \%$ de los entrevistados fueron mujeres y el $37 \%$ hombres, con un edad media de 54 años). En la encuesta, el tamaño teórico de la muestra probabilística dependió de los valores tomados en la varianza poblacional (máxima indeterminación, $\mathrm{p}=50 \%$ y q=50\%), el nivel de confianza ( $\pm 2 \sigma$ del valor medio de la curva de distribución normal, lo que cubre el 95,5\% de las respuestas posibles), el error muestral $( \pm 2 \%)$ y el tamaño del universo. El porcentaje de respuesta obtenido fue del $100 \%$. El análisis descriptivo de la muestra señala que el $50 \%$ de los propietarios encuestados fueron mujeres; el 18,5\% hombres y el 31,5\% fueron propietarios mixtos. De todos ellos, el 18,5\% tenían menos de 40 años; el 38,9\% tenían una edad comprendida entre los 40 y 55 años, y el 42,6\% tenían más de 55 años.

Las encuestas y entrevistas se organizaron en torno a cinco bloques temáticos: 1. El papel del turismo rural en la conservación del paisaje y en la revitalización de la actividad agraria; 2. Conocimiento, percepción y grado de preocupación en relación a la problemática del cambio climático; 3. Percepción de los impactos del cambio climático sobre la actividad agraria y los paisajes de la comarca; 4. Percepción de los impactos del cambio climático sobre el turismo rural de la comarca; y 5. El papel de la Administración en materia de información y actuación frente al cambio climático. Esta secuenciación es la seguida en la exposición de resultados.

\section{RESULTADOS}

\subsection{El papel del turismo rural en la conservación del paisaje y en la revitalización de la actividad agraria}

La implantación de la actividad turística en el medio rural está vinculada, en gran parte, a la atracción que ejercen determinados paisajes dotados de reconocidos valores estéticos, afectivos, ambientales y culturales (Armesto y Gómez, 2012; Gómez y Armesto, 2002). Este hecho convierte a los paisajes rurales en un objeto de consumo que, paradójicamente, puede llegar a ser afectado por la propia actividad turística originada. En este sentido, los agentes encuestados/entrevistados señalan el importante papel que el turismo rural desempeña en la conservación del territorio y el paisaje, así como en el mantenimiento y la revitalización de la actividad agraria (Tabla 2 y 3 y Cuadro 1). Lejos de ahondar en los efectos negativos, los encuestados/entrevistados señalan el beneficioso papel que juegan en la preservación. Los actores son conscientes de que el paisaje es un activo fundamental en cualquier estrategia de desarrollo que se quiera implementar en los espacios rurales y, por ello, son los primeros interesados en su mantenimiento y conservación.

Por otra parte, los entrevistados también señalan la vinculación que existe en la comarca entre producción agraria y turismo. Consideran que el mantenimiento de su actividad agraria está directamente relacionado con el consumo de sus productos por parte de los turistas en los establecimientos de restauración del propio territorio, y añaden que esos turistas pueden funcionar como vectores para la promoción de esos productos una vez retornan a sus localidades de origen (Cuadro 1). 
Tabla 2

VALORACIÓN DEL PAPEL DEL TURISMO RURAL Y DE SU NEGOCIO EN LA CONSERVACIÓN DEL TERRITORIO/PAISAJE

\begin{tabular}{ccc}
\hline Escala (1-7) & $\begin{array}{c}\text { Tuismo rural } \\
(\%)\end{array}$ & $\begin{array}{c}\text { Negocio } \mathbf{~ I R ~} \\
(\%)\end{array}$ \\
\hline 1 & 0 & 0 \\
2 & 0 & 1,9 \\
3 & 0 & 0 \\
1 & 5,6 & 9,3 \\
5 & 13,0 & 5,6 \\
6 & 42,6 & 51,9 \\
7 & 38,9 & 31,5 \\
\hline Total & 100,0 & 100,0 \\
\hline Media & 6 & 6 \\
\hline Moda & 6 & 6 \\
\hline
\end{tabular}

Tabla 3

VALORACIÓN DEL PAPEL DEL TURISMO COMO CONSERVADOR Y REVITALIZADOR DE LA ACTIVIDAD AGRARIA

\begin{tabular}{cc}
\hline Escala (1-7) & $\mathbf{( \% )}$ \\
\hline 1 & 1,9 \\
2 & 0 \\
3 & 14,8 \\
4 & 16,7 \\
5 & 27,8 \\
6 & 33,3 \\
7 & 5,6 \\
\hline Total & 100 \\
\hline Media & 5 \\
Moda & 6 \\
Mediana & 5 \\
\hline
\end{tabular}

4.2. Conocimiento, percepción y grado de preocupación en relación a la problemática del cambio climático

Los actores son conscientes de la problemática del cambio climático, origen y consecuencias (Tabla 4), y muestran elevados niveles de identificación de la problemática (Tabla 5). En este último sentido, el 48,1\% de los encuestados confiesa haber 
detectado personalmente indicios de cambio climático en su entorno, señalando como más palpables los relacionados con la alteración de las estaciones y el aumento de las temperaturas (Tabla 5).

\section{Tabla 4 \\ CUANDO ESCUCHA HABLAR DE CAMBIO CLIMÁTICO, ¿QUÉ ES LO PRIMERO QUE PIENSA O CON QUÉ LO RELACIONA?}

\begin{tabular}{ll}
\hline & $\mathbf{( \% )}$ \\
\hline Fenómeno natural & 5,6 \\
Fenómeno de origen antrópico & 40,7 \\
Detccción de cvidencias o impactos & 37,0 \\
NS/NC & 16,7 \\
Total & 100,0 \\
\hline
\end{tabular}

Tabla 5

INDICIOS DE CAMBIO CLIMÁTICO

\begin{tabular}{|c|c|c|c|}
\hline ¿Ha detectado indicios de cambio climático en su entorno? & Si \% & No $\%$ & Total $\%$ \\
\hline & 48,1 & 51,9 & 100,0 \\
\hline $\begin{array}{l}\text { Principales indicios de cambio climático detectados (para } \\
\text { los que han respondido afirmativamente) }\end{array}$ & $\mathrm{Si} \%$ & No $\%$ & Total \% \\
\hline \multicolumn{4}{|l|}{ Directos } \\
\hline Alteración de las estaciones & 50,0 & 50,0 & 100,0 \\
\hline Aumento de las temperaturas & 38,5 & 61,5 & 100,0 \\
\hline Incremento de los fenómenos meteorológicos extremos & 30,8 & 69,2 & 100,0 \\
\hline Incremento de la variabilidad climática & 30,8 & 69,2 & 100,0 \\
\hline Disminución de las precipitaciones & 23,1 & 76,9 & 100,0 \\
\hline Incremento días ventosos & 7,2 & 92,8 & 100,0 \\
\hline \multicolumn{4}{|l|}{ Indirectos } \\
\hline Incremento del déficit hídrico & 26,9 & 73,1 & 100,0 \\
\hline $\begin{array}{l}\text { Otros (alteraciones fenológicas, alteraciones en la taına, subida } \\
\text { del nivel del mar, etc.) }\end{array}$ & 9,2 & 90,8 & 100,0 \\
\hline
\end{tabular}

El conocimiento que tienen de la problemática y/o la detección de evidencias les hace ser sensibles al fenómeno (Cuadro 1). En este sentido, el 16,7\% de los encuestados manifiesta estar totalmente de acuerdo con la afirmación "Estoy preocupado por la problemática que comporta el cambio climático". El 40,7\% declara estar de acuerdo; el $16,7 \%$ se muestra indeciso, el $25,9 \%$ señala estar en desacuerdo y el $0 \%$ totalmente en desacuerdo. 


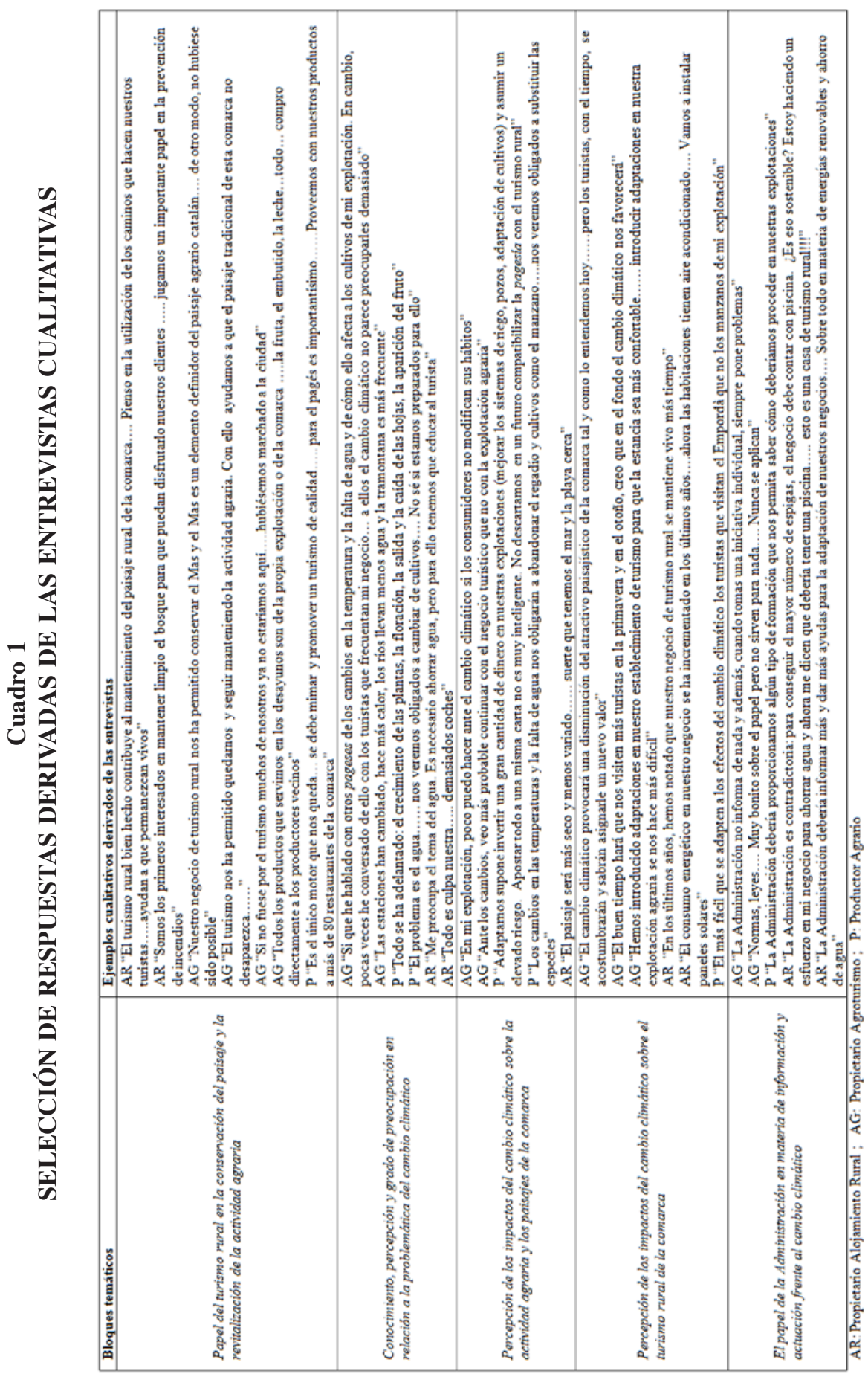




\subsection{Percepción de los impactos del cambio climático sobre la actividad agraria y los paisajes de la comarca}

Los actores muestran una elevada percepción del riesgo que el cambio climático conlleva para la actividad agraria que actualmente se desarrolla en la comarca. De este modo, el 20,4\% de los encuestados manifiesta estar totalmente de acuerdo con la afirmación "El cambio climático comprometerá la actividad agraria de la comarca". El 64,8\% declara estar de acuerdo; el 5,6\% se muestra indeciso, el 7,4\% señala estar en desacuerdo y el 1,9\% totalmente en desacuerdo. Esta misma percepción se pone de manifiesto en las diferentes entrevistas realizadas (Cuadro 1).

Del mismo modo, los encuestados son muy conscientes de las alteraciones paisajísticas que se pueden registrar en el territorio como consecuencia del cambio climático. Así pues, el 13\% manifiesta estar totalmente de acuerdo con la afirmación "La fisonomía del territorio de la comarca se verá transformada por el cambio climático". El 63\% declara estar de acuerdo; el 14,8\% se muestra indeciso, el 9,3\% señala estar en desacuerdo y el $0 \%$ totalmente en desacuerdo. Estos resultados se ven reforzados por las manifestaciones derivadas de las entrevistas (Cuadro 1).

Los actores son conscientes de los potenciales impactos del cambio climático sobre la actividad agraria de la comarca, llegando a visualizar ciertas afectaciones sobre el paisaje de referencia de sus negocios. En este sentido, el 68,5\% de los encuestados cree que los cambios provocarán una mayor aridificación y desertificación de los paisajes (y, por tanto, una disminución del potencial biológico y productivo); el 3,7\% señala que los cambios dibujarán nuevos paisajes derivados de la implementación de cultivos adaptados a los nuevos escenarios y el 7,4\% visualiza afectaciones en la fauna (disminución de insectos polinizadores, proliferación especies invasoras, alteraciones en los procesos migratorios, entre otros). El 20,4\% se mostraba indeciso sobre los nuevos escenarios de futuro o, simplemente, no contestaba. Similares percepciones mostraban buena parte de los actores entrevistados (Cuadro 1).

Los resultados arriba señalados, nos hacen ver la percepción del riesgo que muestran los encuestados/entrevistados, al menos en lo relativo a la actividad agraria y los paisajes. Diversos estudios han demostrado que los individuos con mayor percepción del riesgo son más proclives a la acción y, por tanto, más favorables a implementar o dar apoyo a medidas de adaptación o mitigación que permitan hacer frente al cambio climático (Adger et al., 2009; Bord et al., 1998; O’Connor et al., 2002). Sorprende ver en este caso, que tal afirmación no se cumple: el 31,5\% de los encuestados considera que no se puede hacer nada para reducir impactos o adaptarse a la nueva situación y el $24,1 \%$ se muestra indeciso o no contesta. Son menores los porcentajes que señalan la adopción de iniciativas individuales como la substitución de especies vegetales y cultivos $(5,6 \%)$, la reducción en el consumo de agua $(20,4 \%)$ o los cambios en los hábitos de consumo $(18,5 \%)$. La actitud derrotista, la falta de información y la elevada incertidumbre sobre las acciones que pueden implementar para hacer frente al cambio climático desde la perspectiva del paisaje se manifiesta también en las entrevistas realizadas (Cuadro 1). 


\subsection{Percepción de los impactos del cambio climático sobre el turismo rural de la comarca}

Los actores perciben que los cambios en la actividad agraria y en la fisonomía del territorio conllevarán una pérdida del atractivo paisajístico de la comarca. Así lo evidencian las respuestas a la pregunta "¿El cambio climático comportará una reducción del atractivo paisajístico en el entorno de negocio?": el 59,3\% de los encuestados contestaron afirmativamente; el 18,5\%, negativamente y el 22,2\% NS/NC. Los actores son conscientes de los impactos que el fenómeno puede tener sobre el atractivo turístico de la comarca pero también son conscientes de que todo paisaje, sea del tipo que sea, es potencialmente turístico (Cuadro 1). Con el mismo optimismo, los actores interrogados destacan los efectos beneficiosos que el cambio climático podrá tener sobre el turismo rural de la comarca, debido a la potencial ampliación de la temporada para la práctica de la actividad (Cuadro 1). Desde el punto de vista de los negocios de turismo rural, el cambio climático se percibe como una amenaza distante en el tiempo y con un elevado grado de incertidumbre (Tabla 6 y Cuadro 1).

\section{Tabla 6 \\ ¿CREE QUE EL CAMBIO CLIMÁTICO AFECTA A SU NEGOCIO DE TURISMO RURAL?}

\begin{tabular}{lcc}
\hline & Actualidad (\%) & 20 años (\%) \\
\hline Si & 31,5 & 44,4 \\
No & 61,1 & 9,3 \\
NS/NC & 7,4 & 46,3 \\
Total & 100,0 & 100,0 \\
\hline
\end{tabular}

A diferencia de la actitud mostrada en lo relativo a las medidas de adaptación desde la perspectiva del paisaje, los actores se muestran más proclives y proactivos en materia de adaptación desde la perspectiva del negocio de turismo rural (Cuadro 1). De este modo, son pocos los encuestados que consideran que no se puede hacer nada $(9,3 \%)$ o que los nuevos escenarios obligarán a cerrar el negocio $(1,9 \%)$. Buena parte de los implicados en el sector declaran haber implementado en sus negocios (o estar en vías de hacerlo) medidas que les permitan hacer frente a los impactos detectados o esperados:

- El 44,4\% ha instalado sistemas de acondicionamiento del aire interior y exterior, en la modalidad de opción tecnológica (aire acondicionado, climatización evaporativa), por considerarla la mejor solución para hacer frente al incremento de las temperaturas y a la mayor frecuencia de episodios meteorológicos extremos -como las olas de calor-. El 13\% declara estar en vías de hacerlo.

- El 25,9\% ha optado por utilizar otras vías más sostenibles para acondicionar el aire de los espacios internos y externos (mejoras en el aislamiento de ventanas y puertas, instalación de toldos, sustitución de las especies herbáceas del jardín de la 
casa por especies arbóreas y arbustivas capaces de crear más zonas de sombra). El $11,1 \%$ señala estar en vías de hacerlo.

- El 61,1 \% señala la importancia estratégica de las medidas de optimización del recurso agua para hacer frente a la disminución de los recursos hídricos, manifestando haber implementado alguna medida (instalación de depósitos pluviales, sistemas de ahorro de consumo en las griferías y cisternas, aprovechamiento de aguas grises, acciones comunicativas de ahorro, pozos, etc.). El 11,1\% señala estar en vías de hacerlo.

- El 27,8\% apuesta por la utilización de energías renovables (paneles solares, etc.) y el autoabastecimiento para hacer frente a un previsible incremento en el consumo energético que podría comprometer el suministro eléctrico. El 13\% manifiesta querer adoptar alguna medida en este sentido.

\subsection{El papel de la Administración en materia de información y actuación frente al cambio climático}

Son pocos los actores que atribuyen un papel activo y eficiente a la Administración, ya sea en materia de información o actuación frente al cambio climático. De este modo, tan solo un 5,6\% de los encuestados manifestaron haber recibido ayuda o información de la Administración para adaptar su negocio a los nuevos escenarios de futuro. Los entrevistados (Cuadro 1) declaran que las iniciativas de actuación han partido siempre del ámbito individual y que la Administración ha estado lejos de facilitar o dar apoyo a dichas iniciativas. Señalan que se han realizado muchos esfuerzos en legislar y establecer normativas acordes con los acuerdos internacionales pero que se han realizado pocos esfuerzos en la aplicación (Cuadro 1). Algunos entrevistados también señalan contradicciones de la propia Administración en materia de adaptación y mitigación del cambio climático (Cuadro 1).

Quizás esta "ausencia" de la Administración hace que los actores no acaben de ver cuál puede ser el papel de la misma en todo el proceso o, que simplemente consideren que es mejor que se mantenga al margen (Tabla 7). De este modo, a la pregunta ¿Cómo cree que debería actuar la Administración para afrontar el cambio climático desde el sector turístico?, el 44,4\% contestan NS/NC y el 13\% señalan ser contrarios a la intromisión de la Administración.

Tabla 7

¿CÓMO CREE QUE DEBERÍA ACTUAR LA ADMINISTRACIÓN PARA AFRONTAR EL CAMBIO CLIMÁTICO DESDE EL SECTOR TURÍSTICO?

\begin{tabular}{lc}
\hline & $(\mathbf{\%})$ \\
\hline Sensibilización y transferencia: proporcionando información & 9,3 \\
\hline Financiación: Incrementando las ayudas y subvenciones & 14,8 \\
\hline Instrumentos politicos: Estableciendo planes de actuación a corto y medio plazo & 18,5 \\
\hline Contrarios a la intromisión de la Administración & 13,0 \\
NS/NC & 44,4 \\
Total & 100,0 \\
\hline
\end{tabular}




\section{CONSIDERACIONES FINALES}

Los encuestados/entrevistados son conscientes de la problemática del cambio climático, origen y consecuencias, y son capaces de identificar evidencias en su entorno que pueden tener repercusiones considerables en la preservación de los paisajes actuales y las actividades productivas que sobre ellos se sustentan. Ambas circunstancias les hacen ser sensibles al fenómeno y mostrar interés y preocupación por el mismo. De todos modos, cabe señalar las diferencias existentes en la percepción entre los actores vinculados total o parcialmente a las actividades primarias (propietarios agrarios y propietarios de establecimientos de agroturismo) y los que no mantienen esa vinculación directa (propietarios de establecimientos de alojamiento rural), al observarse en los primeros una mayor sensibilidad hacia la detección de evidencias (Tabla 8). Los actores que mantienen una relación simbiótica con el medio natural parecen demostrar una mejor capacidad para identificar los cambios experimentados, evidenciándose así las conexiones existentes entre percepción del riesgo y contexto socio-cultural y económico (Proctor, 1998; Wildavsky y Dake, 1990).

\section{Tabla 8}

\section{NIVEL DE PERCEPCIÓN DEL CAMBIO CLIMÁTICO POR LOS ACTORES DEL ALT EMPORDÀ}

\begin{tabular}{|c|c|c|c|c|c|c|}
\hline & \multirow[b]{2}{*}{$\begin{array}{l}\text { Detección de } \\
\text { evidencias }\end{array}$} & \multirow[b]{2}{*}{$\begin{array}{c}\text { Grado de } \\
\text { preocupación }\end{array}$} & \multicolumn{2}{|c|}{ Identificación de impactos } & \multicolumn{2}{|c|}{ Adopción medidas de adaptación } \\
\hline & & & $\begin{array}{c}\text { En el paisaje y } \\
\text { la actividad } \\
\text { agraria }\end{array}$ & $\begin{array}{l}\text { En el paisaje y la } \\
\text { actividad turistica }\end{array}$ & $\begin{array}{c}\text { En las explotaciones } \\
\text { agrarias }\end{array}$ & $\begin{array}{c}\text { En el negocio } \\
\text { turistico }\end{array}$ \\
\hline Agroturismo & O & O & 0 & 8 & $\bullet$ & O \\
\hline $\begin{array}{l}\text { Alojamiento } \\
\text { Rural }\end{array}$ & ○ & 0 & O & O & -- & O \\
\hline $\begin{array}{c}\text { Propietarios } \\
\text { agrarios }\end{array}$ & O & 0 & O & ○ & $\bullet$ & -- \\
\hline \multicolumn{7}{|c|}{ - Baja Media } \\
\hline
\end{tabular}

En cuanto a la identificación de impactos y adopción de medidas de adaptación se observan diferencias notables dependiendo de la actividad considerada (Tabla 8 y 9). Los agentes interrogados son conscientes de los potenciales impactos del cambio climático sobre la actividad agraria de la comarca, llegando a visualizar una futura pérdida de potencial productivo. De hecho, los actores perciben que el cambio climático comprometerá la agricultura y ganadería desarrolladas en el Alt Empordà, poniendo en peligro las prácticas que han configurado los paisajes que han dado sustento al turismo rural allí desarrollado. Los actores -por si solos- ven difícil la adopción de medidas de adaptación desde la perspectiva de las explotaciones agrarias, evidenciando una actitud altamente fatalista y derrotista que en ocasiones sugiere o intuye el futuro abandono de la propia actividad primaria. Quizás por ello recriminen a las diferentes Administraciones la falta de ayuda e información. 
Tabla 9

\section{PERCEPCIÓN DEL CAMBIO CLIMÁTICO E IMPACTOS ASOCIADOS POR LOS ACTORES DEL ALT EMPORDÀ}

\begin{tabular}{|c|c|c|c|}
\hline Evidencias percibidas & $\begin{array}{c}\text { Efectos derivados } \\
\text { percibidos }\end{array}$ & Impactos percibidos & Respuestas locales \\
\hline $\begin{array}{l}\text { Alteración de las estaciones. } \\
\text { Aumento de las temperaturas. }\end{array}$ & $\begin{array}{l}\text { Modificación de las } \\
\text { estaciones }\end{array}$ & $\begin{array}{l}\text { Sobre la actividad agraria: } \\
\text { - Pérdida potencial biológico y } \\
\text { productivo. } \\
\text { - Abandono cultivos actuales e } \\
\text { implementación de nucvos cultivos } \\
\text { adaptados a los "nuevos" } \\
\text { escenarios climáticos } \\
\text { - Cambios paisaje. } \\
\text { - Proliferación especies invasoras y } \\
\text { plagas. } \\
\text { Disminución insectos } \\
\text { polinizadores. } \\
\text { Peligro de abandono de las } \\
\text { actividades primarias } \\
\text { Sobre la actividad turística. } \\
\text { - Ampliación de la temporada } \\
\text { turística. } \\
\text { Oportunidad de negocio. } \\
\text { Cambios paisaje. } \\
\text { - Disminución temporal del atractivo } \\
\text { paisajistico. } \\
\text { - Cambio en la imagen turística de la } \\
\text { comarca. } \\
\text { - Incremento del consumo energético } \\
\text { cn los cstablecimicntos. } \\
\text { Aumento de la inversión para lograr } \\
\text { la optimización del recurso agua y } \\
\text { el ahorro energético. }\end{array}$ & $\begin{array}{l}\text { Actividad agraria: } \\
\text { - Substitución especies vegetales } \\
\text { y cultivos (substitución de } \\
\text { frutales por olivar y viñedo). } \\
\text { - Reducción consumo de agua } \\
\text { (substitución sistemas } \\
\text { tradicionales de riego) } \\
\text { Actividad turistica: } \\
\text { - Instalación de sistemas de } \\
\text { acondicionamiento del aire } \\
\text { exterior e interior (opción } \\
\text { tecnológica: aire acondicionado, } \\
\text { climatización evaporativa; opción } \\
\text { no tccnológica: mcjoras cn cl } \\
\text { aislamiento de ventanas y } \\
\text { puertas, instalación de toldos, } \\
\text { sustitución de las especies } \\
\text { herbáceas del jardin de la casa } \\
\text { por especies arbóreas y } \\
\text { arbustivas capaces de crear más } \\
\text { zonas de sombra). } \\
\text { Reducción consumo agua } \\
\text { (instalación de depósitos } \\
\text { pluviales, sistemas de ahomo de } \\
\text { consumo en las griferias y } \\
\text { cisternas, aprovechamiento de } \\
\text { aguas grises, acciones } \\
\text { comunicativas de ahorro, pozos). } \\
\text { - Energías renovables. }\end{array}$ \\
\hline
\end{tabular}

Si el acento se pone en los negocios de turismo rural, aunque los actores son conscientes de los impactos que el fenómeno puede tener sobre el atractivo turístico de la comarca, se muestran menos preocupados al considerar que todo paisaje, sea del tipo que sea, es potencialmente turístico $\mathrm{y}$, por tanto, las repercusiones sobre los negocios de turismo rural no tienen por qué ser negativas si los establecimientos son capaces de proporcionar a los usuarios unas adecuadas condiciones de confort, seguridad y disfrute. El cambio climático nos obligará a, como señala Urry (1990), cambiar la forma en que miramos los paisajes que constituyen la experiencia turística. El proceso de adaptación a estos paisajes modificados se convertirá en un reto -superable- para los propios consumidores de ellos pero también para los diferentes agentes y actores conformadores del mismo (Gómez Martín y López, 2001). Quizás por ello, desde la perspectiva del negocio de turismo rural y teniendo en cuenta la previsible ampliación de los calendarios de potencialidad turística, se observe mayor proactividad en materia de adaptación. Los actores implicados han manifestado que ya han implementado medidas de adaptación en sus negocios o están en vías de hacerlo y, en la mayoría de los casos, suponen respuestas individuales y puntuales a problemas concretos (sin incentivación ni intervención de las instituciones). Las opciones de adaptación más desarrolladas han sido las que se mueven en el ámbito de trabajo 
de las tecnologías (estas son mayoritarias), las que tienen que ver con el management y la gestión del negocio y las relativas al comportamiento-educación. Muchas de estas opciones de adaptación pueden ser consideradas a la vez acciones de mitigación al cambio climático, lo que viene a demostrar las sinergias existentes entre adaptación y mitigación en las acciones desarrolladas a escala local y que también han sido puestas de manifiesto en otros casos de estudio (Campos et al., 2013; Locatelli, 2010).

Pero la percepción del riesgo también influye en la creación de barreras subjetivas a las acciones de adaptación y, por extensión, mitigación del cambio climático (Figura 3). Así, los actores aquí considerados han manifestado percibir los impactos del cambio climático como una amenaza a medio plazo, con un elevado grado de incertidumbre. La percepción del cambio climático como un fenómeno incierto y no cercano en el tiempo constituye una barrera que puede ralentizar los procesos de adaptación. Del mismo modo, la excesiva confianza en la opción tecnológica para resolver buena parte de los impactos derivados del cambio climático puede actuar como una barrera de cara a la implementación de otras opciones más sostenibles. En este sentido, podría suceder que lo que una buena parte de los propietarios perciben como una óptima estrategia de adaptación, entre en conflicto con los discursos defendidos por los organismos públicos de acuerdo con los compromisos internacionales en materia de cambio climático.

Figura 3

\section{MATRIZ CUALITATIVA SOBRE LA IMPORTANCIA DE LAS BARRERAS DETECTADAS PARA LA ADAPTACIÓN AL CAMBIO CLIMÁTICO}

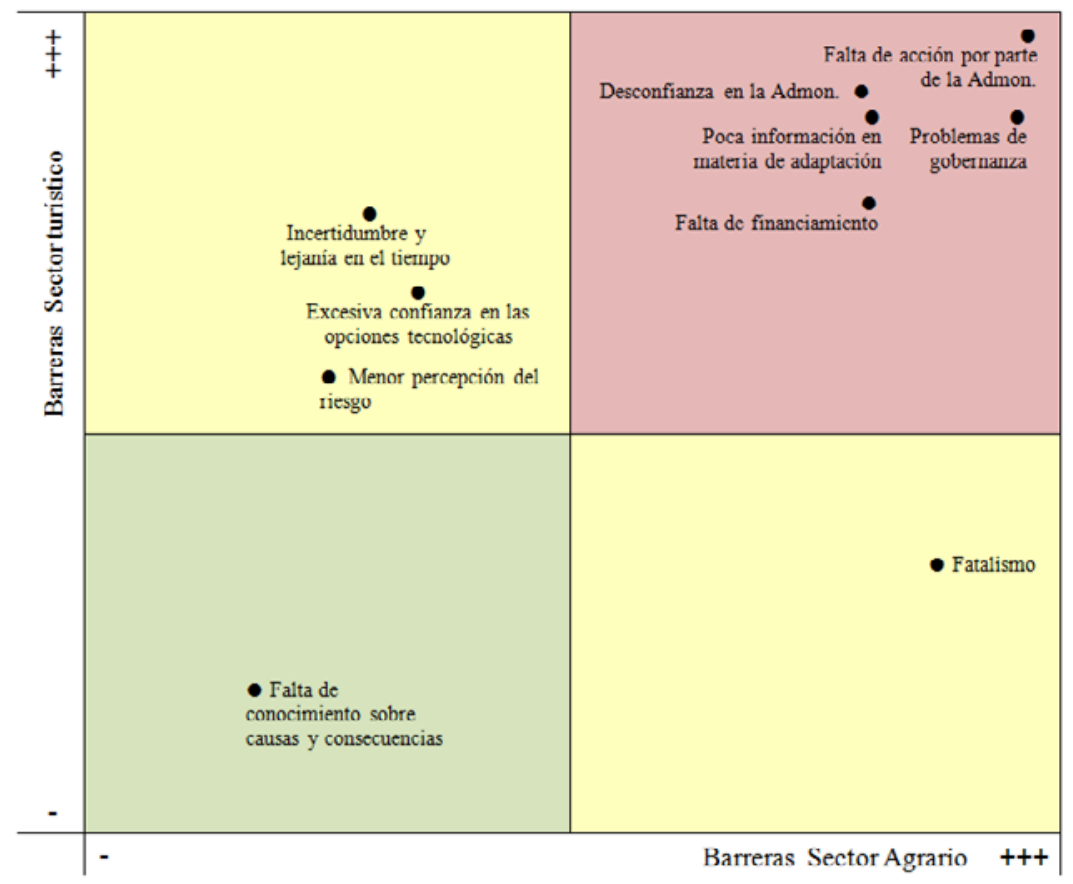


Tanto desde el punto de vista de los negocios de turismo rural como de las explotaciones agrarias, se ha puesto en evidencia -por parte de los actores del territorio- la falta de conocimiento o, en ocasiones, la inexistencia de instrumentos institucionales para la gestión del riesgo y adaptación al cambio climático. De hecho, hasta el momento, las estrategias desarrolladas en el ámbito de los negocios de turismo rural o de las explotaciones agrarias son estrategias cuya elección y aplicación han dependido única y exclusivamente de la voluntad o necesidad del propietario (es decir, sin intervención de instituciones ajenas al propio negocio o explotación). En este sentido, los actores poco nos dicen de acciones que superen el ámbito estrictamente individual como, por ejemplo, las estrategias de mercado desarrolladas, las estrategias de externalización del riesgo que permitan compartir el peligro con otras empresas, los instrumentos políticos de apoyo (exención de impuestos, ayudas directas, préstamos con bajo interés, etc.) o los instrumentos específicos de gestión de riesgos en el marco de la PAC (esto último sólo para el caso de los propietarios agrarios y propietarios de establecimientos de agroturismo). La desconfianza hacia la clase política y la Administración Pública, en parte generada por el alejamiento y la desconexión de éstos con la población y los pequeños empresarios -no debemos olvidar que el sector considerado está formado mayoritariamente por pequeñas empresas de carácter familiar-, ha provocado - de forma casi generalizada- una falta de colaboración y entendimiento entre los actores aquí contemplados y las instituciones. De no evitarse esta situación se podría poner en peligro la eficacia o eficiencia de las políticas de lucha frente al cambio climático que se pudieran desarrollar o "concretar" en el futuro.

Por último, conviene recordar que explorar la cuestión aquí abordada resulta extremadamente complejo ya que la multifuncionalidad de los paisajes rurales recomienda la consideración de los diversos actores que intervienen en su configuración y gestión. En este sentido, la percepción del riesgo que muestran otros actores implicados se configura como una futura vía de trabajo que ayudará a complementar y matizar los resultados aquí presentados.

\section{BIBLIOGRAFÍA}

ADGER, W.N.; DESSAI, S.; GOULDEN, M.; HULME, M.; LORENZONI, I.; NELSON, D.R.; NAESS, L.O.; WOLF, J.; WREFORD, A. (2009): «Are there social limits to adaptation to climate change?», Climatic Change, $\mathrm{n}^{\circ}$ 93, pp. 335-354.

ALBERTÍ, A.; GORDI, J. (2009): Carta del Paisatge del Alt Empordà. Barcelona, Generalitat de Catalunya.

ARMESTO LÓPEZ, X.; GÓMEZ MARTÍN, M.B. (2012): «How do organic farmers regard tourism? Reflections of farmers from the Alt Empordà area», European Journal of Tourism, Hospitality and Recreation, $\mathrm{n}^{\mathrm{o}} 3$, pp. 11-28.

ARMESTO, X.; GÓMEZ MARTÍN, M.B.; CORS M. (2014): «Paisaje agrario y turismo rural. La visión de los agentes en Cataluña en base a las incertidumbres que genera el cambio climático», en Pavón, D. et al. (Eds.): Revalorizando el espacio rural: leer el pasado para ganar el futuro.

BARRIOS, S.; IBAÑEZ, N. (2015): «Time is of the essence: adaptation of tourism demand to climate change in Europe», Climatic Change, $\mathrm{n}^{\circ} 132$ (4), pp. 645-660. 
BECKEN, S. (2005): «Harmonising climate change adaptation and mitigation: The case of tourist resorts in Fiji», Global Environmental Change, n 15 , pp. 381-393.

BECKEN, S. (2013): «A review of tourism and climate change as an evolving knowledge domain», Tourism Management Perspectives, $n^{\circ}$ 6, pp. 53-62.

BECKEN, S.; ZAMMIT, C.; HENDRIKX, J. (2014): «Developing climate change maps for tourism essential information or awareness raising?», Journal of Travel Research, DOI: $10.1177 / 0047287514528286$.

BELLE, N.; BRAMWELL, B. (2005): «Climate change and small island tourism: policymaker and industry perspectives in Barbados», Journal of Travel Research, $\mathrm{n}^{\circ} 44$ (1), pp. 32-41.

BORD, R.J.; FISHER, A.; O'CONNOR, R. (1998): «Public perceptions of global warming: United States and international perspectives», Climate Research, ${ }^{\circ} 11, \mathrm{pp} .75-84$.

BUCKLEY, R. (2008): «Misperceptions of climate change damage coastal tourism: case study of Byron Bay, Australia», Tourism Review International, $\mathrm{n}^{\circ}$ 12(1), pp. 71-88.

BUZINDE, C.N.; MANUEL, D.; YOO, E.; MORAIS, D. (2010): «Tourists’ perceptions in a climate of change: Eroding Destinations», Annals of Tourism Research, $\mathrm{n}^{\circ} 37$ (2), pp. 333-354.

CAMPOS, M.; HERRADOR, D.; MANUEL, C.; MCCALL, M. (2013): «Estrategias de adaptación al cambio climático en dos comunidades rurales de México y El Salvador», Boletín de la Asociación de Geógrafos Españoles, nº 61, pp. 329-352.

CÀNOVES, G.; HERRERA, L.; VILLARINO, M. (2005): «Turismo rural en España: paisajes y usuarios, nuevos usos y nuevas visiones», Cuadernos de Turismo, $\mathrm{n}^{\circ} 15$, pp. 63-76.

DELYSER, D.; SUI, D. (2013): «Crossing the qualitative- quantitative divide II. Inventive approaches to big data, mobile methods, and rhythmanalysis», Progress in Human Geography, no 37 (2), pp. 293-305.

DELYSER, D.; SUI, D. (2014): «Crossing the qualitative-quantitative chasm III. Enduring methods, open geography, participatory research, and the fourth paradigm», Progress in Human Geography, no 38, pp. 294-307.

ERIKSEN, S.; SELBOE, E. (2012): «The social organisation of adaptation to climate variability and global change: The case of a mountain farming community in Norway», Applied Geography, n 33 , pp. 159-167.

ESPEJO MARÍN, C. (2011): «El paisaje como recurso turístico», en Simancas, M.R. et al. (Coords.): Retos y perspectivas de la gestión del Paisaje de Canarias. Santa Cruz de Tenerife, Gobierno de Canarias y Universidad Internacional Menéndez Pelayo, pp. 337-461.

GARCÍA-RUIZ, J.M.; LÓPEZ, J.I.; VICENTE, J.; LASANTA, T.; BEGUERÍA, S. (2011): «Mediterranean water resources in a global change scenario», Earth-Science Reviews, $\mathrm{n}^{\circ} 105$, pp. 121-139.

GÓMEZ MARTÍN, M.B.; LÓPEZ, F. (2001): «Tourism, territory and marginality. Principles and case studies», in Annual Conference of International Geographical Union, Commission on Evolving Issues of Geographic Marginality in the Early 21st Century World, Stockholm. 
GÓMEZ MARTÍN, M.B.; ARMESTO, X. (2002): «Turismo, gastronomía y territorio», en Los espacios rurales entre el hoy y el mañana. Santander, Pub. Universidad de Cantabria, Asociación de Geógrafos Españoles (AGE) y Grupo de Geografía Rural, pp. 139-147.

GÓMEZ MARTÍN, M.B. (2005a): «Weather, climate and tourism a geographical perspective», Annals of Tourism Research, $\mathrm{n}^{\circ} 32$ (3), pp. 571-591.

GÓMEZ MARTÍN, M.B. (2005b): «Reflexión geográfica en torno al binomio climaturismo», Boletín de la Asociación de Geógrafos Españoles, ${ }^{\circ}$ 40, pp. 111-134.

GÓMEZ MARTÍN, M.B.; MARTÍNEZ, E. (2012): «Tourism demand and atmospheric parameters: Non-intrusive observation techniques», Climate Research, n ${ }^{\circ}$ 51, pp. 135 145.

GÓMEZ MARTÍN, M.B.; ARMESTO, X.; MARTÍNEZ , E. (2014): «The Spanish tourist sector facing extreme climate events: a case study of domestic tourism in the heat wave of 2003», International Journal of Biometeorology, $n^{\circ}$ 58, pp. 781-797.

GÓMEZ MARTÍN, M.B.; ARMESTO, X.; CORS, M.; MUÑOZ, J. (2014): «Adaptation strategies to climate change in the tourist sector: the case of coastal tourism in Spain», Tourism: An International Interdisciplinary Journal, $\mathrm{n}^{\circ} 62$ (3), pp. 293-308.

GÖSSLING, S.; BREDBERG, M.; RANDOW, A.; SANDSTRÖM, E.; SVENSSON, P. (2006): «Tourist perceptions of climate change: a study of international tourists in Zanzibar», Current Issues in Tourism, no 9 (4-5), pp. 419-435.

GÖSSLING, S.; SCOTT, D.; HALL, C.M.; CERON, J. P.; DUBOIS, G. (2012): «Consumer behaviour and demand response of tourists to climate change», Annals of Tourism Research, $\mathrm{n}^{\circ} 39$ (1), pp. 36-58.

HALL, C.M. (2006): «New Zealand tourism entrepreneur attitudes and behaviours with respect to climate change adaptation and mitigation», International Journal of Innovation and Sustainable Development, $\mathrm{n}^{\circ} 1$ (3), pp. 229-237.

HEIN, L.; METZGER, M.J.; MORENO, A. (2009): «Potential impacts of climate change on tourism; a case study for Spain», Current Opinion in Environmental Sustainability, $\mathrm{n}^{\circ} 1$, pp. 170-178.

HERNÁNDEZ, M. (2009): «El paisaje como seña de identidad territorial: valorización social y factor de desarrollo, ¿utopía o realidad?», Boletín de la Asociación de Geógrafos Españoles, n ${ }^{\circ} 49$, pp. 169-183.

HOF, A.; SCHMITT, T. (2011): «Urban and tourist land use patterns and water consumption: Evidence from Mallorca, Balearic Islands», Land Use Policy, n 28, pp. 792-804.

HUGHES, L. (2000): «Biological consequences of global warming: is the signal already apparent?», Trends in Ecology and Evolution, $\mathrm{n}^{\circ} 15$, pp. 56-61.

IDESCAT (2014): Anuari estadístic de Catalunya 2014. Barcelona, Generalitat de Catalunya.

IGLESIAS, A.; GAROTE, L.; DIZ, A.; SCHLICKENRIEDER, J.; MARTÍN, F. (2011): «Re-thinking water policy priorities in the Mediterranean region in view of climate change», Environmental Science and Policy, n 14 , pp. 744-757.

KLINT, L.M.; JIANG, M.; LAW, A.; DELACY, T.; FILEP, S.; CALGARO, E.; DOMINEY, D.; HARRISON, D. (2012): «Dive tourism in Luganville, Vanuatu: shocks, stressors, and vulnerability to climate change», Tourism in Marine Environments, nº 8(1), pp. 91-109. 
LOCATELLI, B. (2010): «Local, global: intégrer atténuation et adaptation», CIRAD, Perspective: Forets/Changement Climatiques, $\mathrm{n}^{\circ} 3$, pp. 4.

LORENZONI, I.; NICHOLSON-COLE, S.; WHITMARSH, L. (2007): «Barriers perceived to engaging with climate change among the UK public and their policy implications», Global Environmental Change, nº 17 (3), pp. 445-459.

LLAUSÀS, A.; RIBAS, A.; VARGA, D.; VILA, J. (2009): «The evolution of agrarian practices and its effects on the structure of enclosure landscapes in the Alt Empordà (Catalonia, Spain), 1957-2001», Agriculture, Ecosystems and Environment, $\mathrm{n}^{\circ}$ 129(1), pp. 73-82.

MARTÍ, C.; PINTÓ, J. (2012): «Cambios recientes en el paisaje litoral de la Costa Brava», Documents d'Anàlisi Geogràfica, no 58 (2), pp. 239-264.

MARTÍNEZ IBARRA, E.; GÓMEZ MARTÍN, M.B. (2012): «Weather, climate and tourist behaviour: the Beach tourism of the Spanish Mediterranean coast as a case study», European Journal of Tourism, Hospitality and Recreation, $\mathrm{n}^{\circ}$ 3, pp. 77-96.

MARTÍNEZ IBARRA, E (2015): «Climate, water and tourism: causes and effects of droughts associated with urban development and tourism in Benidorm (Spain)», International Journal of Biometeorology, $\mathrm{n}^{\circ}$ 59, pp. 487-501.

MCEVOY, D.; CAVAN, G.; HANDLEY, J.; LINDLEY, S. (2008): «Changes to climate and visitor behaviour: implications for vulnerable landscapes in the Northwest region of England», Journal of Sustainable Tourism, $\mathrm{n}^{\circ}$ 16, pp. 101-121.

MERTZ, O.; MBOW, C.; REENBERG, A.; DIOUF, A. (2009): «Farmers' perceptions of climate change and agricultural adaptation strategies in rural Sahel», Environmental Management, $\mathrm{n}^{\circ}$ 43(5), pp. 804-816.

NOGUÉ, J. (1989): «Paisaje y turismo», Estudios Turísticos, n 103, pp. 35-45.

O'CONNOR, R.E.; BORD, R.J.; YARNAL, B.; WIEFEK, N. (2002): «Who wants to reduce greenhouse gas emissions?», Social Science Quarterly, nº 83, pp. 1-17.

OLCINA CANTOS, J. (2012): «Turismo y cambio climático: una actividad vulnerable que debe adaptarse», Investigaciones Turísticas, $\mathrm{n}^{\circ}$ 4, pp. 1-34.

PRAT, J.M.; CÀNOVES, G. (2014): «Análisis de la evolución de la concentración geográfica de los establecimientos de turismo rural en Cataluña», Anales de Geografía de la Universidad Complutense, $\mathrm{n}^{\circ} 34$ (1), pp. 155-177.

PRIDEAUX, B.; COGHLAN, A.; MCNAMARA, K. (2010): «Assessing tourists perceptions of climate change on mountain landscapes», Tourism Recreation Research, $\mathrm{n}^{\circ}$ 35(2), pp. 187-199.

PROCTOR, J.D. (1998): «The meaning of global environmental change: retheorizing culture in human dimensions research», Global Environmental Change, $\mathrm{n}^{\circ} 8$ (3), pp.227- 248.

RIBAS, A.; CALBÓ, J.; LLAUSÀS, A.; LÓPEZ-BUSTINS, J.A. (2010): «Climate change at the local scale: Trends, Impacts and Adaptations in a Northwestern Mediterranean Region (Costa Brava, NE Iberian Peninsula) », The International Journal of Climate Change. Impacts and Responses, $\mathrm{n}^{\circ} 2(1)$, pp. 247-264.

RICO AMOROS, A.M.; OLCINA, J.; SAURÍ, D. (2009): «Tourist land use patterns and water demand: evidence from the western Mediterranean», Land Use Policy, $\mathrm{n}^{\circ} 26$, pp. 493-501. 
RUTTY, M., \& SCOTT, D. (2010): «Will the Mediterranean Become “Too Hot” for Tourism? A Reassessment», Tourism and Hospitality Planning and Development, $\mathrm{n}^{\circ} 7$ (3), pp. 267-281.

SAARINEN, J.; TERVO, K. (2010): «Sustainability and emerging awareness of a changing climate», in Hall, C.M. et al. (Eds.): Tourism and change in polar regions: Climate, Environments and Experiences. Routledge, pp. 147-164.

SCOTT, D.; JONES, B.; KONOPEK, J. (2008): «Exploring potential visitor response to climate-induced environmental changes in Canada>s Rocky Mountain national parks», Tourism Review International, $\mathrm{n}^{\mathrm{o}} 12$ (1), pp. 43-56.

SCOTT, D.; HALL, C.M.; GÖSSLING, S. (2012): Tourism and climate change: Impacts, adaptation and mitigation, Vol. 10. Routledge.

SERRA, P.; SAURÍ, D.; PONS, X. (2004): «Evolució recent del paisatge agrari de l'Alt Empordà a través de teledetecció i d'índexs paisatgístics», Treballs de la Societat Catalana de Geografia, no 57, pp. 237-256.

STROBL, A.; STEIGER, R.; PETERS, M.; WEIERMAIR K. (2011): «Tourismusforschung und - praxis: Wen kümmert der Klimawandel?», In Bieger, T. et al. (Eds.): Wettbewerb im alpinen Tourismus - Herausforderungen und Innovationen. Schweizer Jahrbuch für Tourismus 2010. Berlin, Erich Schmidt Verlag, pp. 105-114

SUI, D.; DELYSER, D. (2012): «Crossing the qualitative quantitative chasm I: Hybrid geographies, the spatial turn, and volunteered geographic information (VGI)», Progress in Human Geography, no 36(1), pp. 111-124.

TASHAKKORI, A.; TEDDLIE C. (1998): Mixed Methodology, Combining Qualitative and Quantitative Approaches. London, Sage Publications.

TASHAKKORI, A.; TEDDLIE, C. (2010): «The past and future of mixed methods research: From triangulation to mixed model design», In Tashakkori, A. et al. (Eds.): Handbook of Mixed Methods in Social and Behavioral Research. Sage, pp. 671-701.

TRAWÖGER, L. (2014): «Convinced, ambivalent or annoyed: Tyrolean ski tourism stakeholders and their perceptions of climate change», Tourism Management, $\mathrm{n}^{\circ} 40$, pp. 338-351.

URRY, J. (1990): The Tourist Gaze. London, Sage.

VALLS, F.; SARDÁ, R. (2009): «Tourism expert perceptions for evaluating climate change impacts on the Euro-Mediterranean tourism industry», Tourism Review, nº 64 (2), pp. 41-51.

WILBANKS, T.J. (2003): «Integrating climate change and sustainable development in a place-based context», Climate Policy, n $3-1$, pp. 147-154.

WILDAVSKY, A.; DAKE, K. (1990): «Theories of risk perception: Who fears what and why?», Daedalus, no 119 (4), pp. 41-60.

WYSS, R.; ABEGG, B.; LUTHE, T. (2014): «Perceptions of climate change in a tourism governance context», Tourism Management Perspectives, $\mathrm{n}^{\circ}$ 11, pp. 69-76.

WOLFSEGGER, C.; GÖSSLING, S.; SCOTT, D. (2008): «Climate change risk appraisal in the Austrian ski industry», Tourism Review International, $\mathrm{n}^{\circ} 12$ (1), pp. 13-23. 